\title{
Research on the Student Centered Teaching in the Course of Principles of Electric Circuit
}

\author{
Yumei Li ,Tao Wu, Anren Ma \\ Electrical Engineering College of Northwest Minzu University \\ Lanzhou, China
}

\begin{abstract}
How to guide the ordinary college students to learn the content of the electric circuit course well has been a challenge for teachers. As we all know it is imperative to improve the teaching method here and now. According to the characteristics of the circuit course, developing the students centered teaching mode can receive good results. The more important is that teachers need to extract the key point hidden in the text and to present it in the way that easy to understand for students, then knowledge becomes simple and profound. Guiding exploratory learning is a good choice.
\end{abstract}

Keywords-electric circuit course; teaching method; students centered teaching mode

\section{INTRODUCTION}

The predecessor of the circuit is electromagnetism, now it has evolved into the most basic content of electronic and electrical disciplines. Located in the bottom of the electrical and electronics knowledge pyramid, circuit course provides good support for professional knowledge as well. The learning Outcomes of the electric circuit course plays an important role in the study of the content of the following courses. As electric circuit course teachers or electric circuit curriculum guides, we must explore a better teaching method in the teaching process of student centered teaching concept [1]. Teachers lead students to find the simple and profound point, to experience the happiness and the fun of learning.

Teaching should be student centered and teachers leading [2], and it can be divided into the theoretical part, experimental teaching, extracurricular research and communication, exploration and practice of research learning in engineering practice. At the same time, the traditional classroom teaching mode should be changed into integrated comprehensive one, and it is necessary to enrich the teaching methods and teaching contents.

\section{FOCUS ON THE ESTABLISHMENT OF CIRCUIT MODEL}

\section{A. Establishment of circuit model}

The establishment of the knowledge system of circuit curriculum is based on the circuit model, and the course content is based on the circuit model. In fact, the circuit model is a simplified model representing the basic physical properties of the actual circuit, and it is also a mathematical model with the relationship between the voltage and current in the circuit. Voltage and current constraints are mainly Kirchhoff's law and the relationship between the voltage and current of resistance, inductance, capacitance, transistors, diodes and electric sources .When the qualitative analysis of the actual circuit is required, a circuit model runs in front.

\section{B. Application of mathematical method}

On the basis of the circuit model, the analysis of the circuit is transformed into the establishment of mathematical equations. The calculation of the circuit is transformed into solving the circuit equation. When the mathematical methods applied into circuit analysis, the most important is the reference direction. With the definition of the reference direction and the associated reference direction of voltage, current and power, the value of voltage, current and power are divided into positive or negative .The analysis and calculation of the circuit model can be expanded by mathematical equations, which reflects the unity between the direction of physical quantity and the positive or negative value in the actual engineering.

For example, in dynamic circuit analysis which is about circuit includes Inductance and capacitance transit from one steady state to another. It requires the combination of mathematical methods and circuit models. The critical factors are the relationship between voltage and current on the capacitor or inductance and the energy storage on the inductance or capacitor. When the circuit is in a steady state, the energy storage on the inductance or capacitor is changeless. For the capacitor, the voltage of the capacitor is not changed, then the capacitance current is zero, and the capacitance is equal to an open circuit. Therefore, in the steady-state circuit, the capacitor can be processed as an open circuit. When the circuit is in stable state, the current on the inductance is not changed, then the inductance voltage is zero, and the inductance is equivalent to a short circuit. On the moment of the circuit changed, 0 - time is actually the final moments before the changing, $0+$ moment is the first time after the changing. For the $\infty$ moment is not the time when the earth and heaven get old, it is marking circuit have reached the steady state. On the moment of the circuit is changed, energy is not able to change transiently, that is the capacitor voltage cannot change abruptly, the inductance current is not change abruptly yet, which give expression to the electric charge conservation and the inductance flux conservation. The transition from $0+$ to zero is the process of energy transition, which is also the transition process of capacitor voltage and inductor current.

The modeling process also makes a good explanation for the function of the physics, calculus, linear algebra course 
which has learned before. At the same time, it may Avoid disconnection between learning content before and after, urge the students to learn more college courses, correct negative opinion of some courses are useless.

Furthermore, circuit elements constitute a circuit, the same component in different engineering background requires different models.

\section{TEACHING AS TELLING STORIES}

Introduce the model of telling stories in Teaching. This is an effective way to cultivate students' interest in learning, so that students can experience the fun of learning.

\section{A. Create conflict between knowledge points}

When establish the basic knowledge system step by step, heuristic teaching method can be a good choice. As telling stories, teachers have a mind to create conflict between some knowledge points in class, which guides students to find problems, to think about the solving method, to enhance their interest in learning meanwhile. In this process, students can get the joy of there is a way out in learning themselves. Such as: phasor is a complex expresses for a sinusoidal quantity, impedance is not a phasor yet, why they could do operation in the same expression. That is for impedance is a complex whose real part is resistance, imaginary part is reactance too.

Another example: could the three factor method can be used to calculate the voltage or current of resistances or independent sources directly. When you throw this question, it may inspire students to think about the answer, when get the correct answer, make a questioning why the three factor method could only be used to calculate the current of the inductance or the capacitor voltage further. This maybe a student centered teaching.

\section{B. Analogy or contrast}

With understand of students oriented, cited specific examples around them, by analogy or contrast to find similarities and differences between the knowledge and the examples. For example, phasor method is used in the analysis of sinusoidal steady state circuit commonly. Students can be told that the phasor is a stand-in for the sinusoidal, instead of the sinusoidal quantity to be involved in the circuit equation column, instead of the sine one to do the calculation, the calculation results return to the sine finally in the process. When the phasor method is used, the differential and integral operations of the sinusoidal curve are shown in Table 1.

TABLE I. DIFFERENTIAL CALCULUS AND INTEGRAL OPERATION OF SINUSOIDAL QUANTITY WHEN PHASOR METHOD IS EMPLOYED

\begin{tabular}{|l|l|c|}
\hline $\begin{array}{c}\text { Representation } \\
\text { and operation }\end{array}$ & \multicolumn{1}{c|}{ Sinusoidal quantity } & Phasor method \\
\hline variable & $i=\sqrt{2} I \cos \left(\omega t+\psi_{i}\right)$ & $\dot{I}=I \angle \psi_{i}$ \\
\hline differential & $u_{l}=L \frac{d i}{d t}$ & $\dot{U}_{l}=j \omega L I \angle \psi_{i}$ \\
\hline integral & $u_{c}=\frac{1}{C} \int i d t$ & $\dot{U}_{l}=\frac{1}{j \omega C} I \angle \psi_{i}$ \\
\hline
\end{tabular}

From the table, when sinusoidal quantity is replaced by phasor method, the differential operation can be expressed as the phasor multiplied by $j \omega$, the integration can be expressed as the phasor divided by $j \omega$. The list and make the knowledge structure more clearly at the same time.

\section{Create a lively and vivid classroom atmosphere}

On the other hand, create a lively and vivid classroom atmosphere, takes love and joy for the pursuit of knowledge to students, then students maybe infected. Tell the stories of scientists and seeking knowledge from naming. For example, the resistance of the ideal voltage source is not divided, so it becomes zero, the resistance of ideal current source don't split current, so it becomes infinity. In the sinusoidal steady state circuit, the resistance is similar to sprue in the water pipe, the size does not change with the current, while the value of reactance changes with frequency, the strength of resistance changes with rivals in a certain range, strong to strong, weak to weak. Meanwhile, the inductive reactance and capacitive reactance reflect different attitude for life and personality characteristics in the circuit. The inductive character is strong woman do not love the change of electric current, the larger the frequency of current change the stronger resistance and the greater the inductance. The capacitance is man love changes, the current frequency changes more quickly, the more joy, the smaller of the capacitance yet.

\section{TEACHING AS EXPLORING}

In class, teachers should be a guide for the audience to explore, to stimulate the learning initiative, allowing them to experience learning by themselves. The flexibility and creativity of the thinking can be stimulated in the position of the master of study. Finally, a reasonable and appropriate summary can be a popular presenting.

\section{A. Exploring how to turn the complex into simple}

Human beings have never abandoned the search for turn complicated problems into simple. In a resistance circuit, multiple resistors are usually equivalent to a resistor, and the role of multiple sources is equivalent to a power supply. When there are many kinds of circuit elements in a linear circuit, it is divided into a series of simple components at first, then the characteristics of the individual components is analyst the complex becomes a simple problem.

The self-introduction of a part of the circuit is VCR, that is, the voltage, current and resistance. However the guests of the famous TV program named you are the one introduced themselves by VCR. To let students understand the basic characteristics of the circuit components is the volt ampere characteristics in a second.

When the complex circuit is transformed into a simple circuit, it is ensured that which is the correct transformation the voltage between terminals is the same and the current on the terminal is invariable.

When teaching as exploring, teachers must be proficient in the context of teaching materials, leading students to explore knowledge structure, the root of the knowledge structure, the trunk, the branches and the leaves. The basic which is simple as well is the root of the complex usually. 


\section{B. Create opportunities for learning themselves}

The ability of autonomous learning is a skill that college students must master. In the student centered teaching, teachers need to create opportunities for self-study to improve the selflearning ability. When teaching the circuit, teachers can leave the substitution theorem behind for students to learn by themselves.

To teach fishing is better than to fish, cultivate students' ability of autonomous learning is better than tell students knowledge. In the self-learning, students can sum up their own knowledge point which is simple and profound.

\section{COMBINING THEORY WITH EXPERIMENT}

For engineering discipline, experiment is indispensable supplement of theory in Inquiry Learning and Heuristic Teaching [3]. Experiment is the source of knowledge and judgment of theory as well. The experiment can be an important ruler to make sure the theory is reasonable. Throughout the history of the development of all engineering disciplines, many important theories and laws are derived from the experiment.

Because of college entrance examination in china, the selflearning awareness still stay with most of the students, but the autonomous learning ability has not been cultivated yet. Students should be encouraged to carry out the exploration and innovation which are based on the experiment. When the new teaching model is introduced in the experimental in addition it not only helps the students to cultivate learning enthusiasm, but also reflect the demands of from the experiment, to the practice for engineering professional learning.

\section{A. Students encounter problems in the experiment}

Experiments can provide a broad space for thinking and choices for students, so that the creative consciousness and comprehensive ability are inspired and exercised.

It is often happens that students connect the lines according to circuit diagram, then recording the measured data to finish the laboratory report in the experiment. The student's potential has not been excavated, and the initiative has not been due to play. The completely different is when students encounter problems in the experiment, they will be pushed to the job to solve the problems, then continuous thinking and repeated attempts will be followed, to search the knowledge in mind desperately, to find the source of the problem, and explore solutions to the problem encountered. It is ever better that intense learning by discussion and high efficiency learning with communication will be launched in silence.

If the crux of the problem is found, the students is encouraged, if the way to solve the problem comes to light, students may be very excited for the experience of the meaningful learning, and get self-recognition too. This selfrecognition will be a positive energy to encourage students to continue learning. The worst result is that students can't find the root of the problem themselves, the guidance and inspiration from teachers become important especially. Skillful guidance can lead students to go on the road leading to the right answer step by step, so that students will eventually reach the correct answer too. It may also cause them to think about how to make the right judgments, how to find the the crux of the problem, the experiment is worth it.

\section{B. Introduce MATLAB software into the classroom}

With the great progress of science and technology now, the computer is efficient and popular in solving the equations problem, the artificial calculation which is boring enough is fading out. The circuit course requires students to master the method of circuit analysis, namely listing equation in different method, not the ability in solving equations. Based on this idea, the MATLAB software is introduced into the classroom. Use a different method, through the preparation of procedures to analyze the circuit, with the computer to get results.

For the same circuit, using different methods to list equations as usual at first, get the results through the preparation of program for analysis circuit. In particular, when the complex number and phasor are involved in the analysis of the circuit, the advantages of MATLAB software highlight as it is used to save a lot of time. At the same time guide students to set up the circuit model in the Simulink module to observe the waveform of voltage or current then compare it with the waveform obtained by programming. While validating the programming, the students master a new skill. The simulation model is shown in Fig. 1.

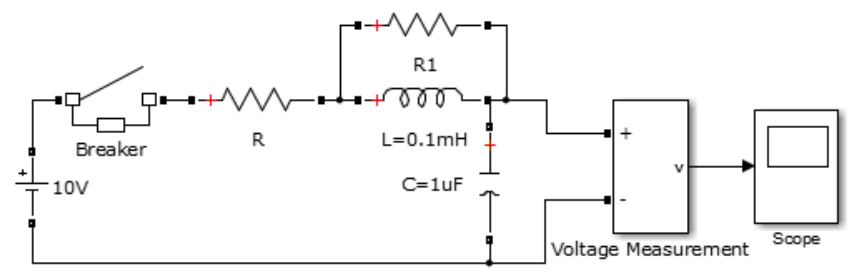

Fig. 1. The simulation model

For dynamic circuit analysis, MATLAB shows the perfect parameters of the waveform, and these wave forms will enable students to have a clearer understanding of the circuit function and characteristics as shown in Fig. 2.

\section{Inspire students to design experiments independently}

When adopting the project based leaning and conceive design implement operation [4-5], inspire students to design experiments independently may play an active role.

Select some common practical circuit of life and teachers can require students to design it in the laboratory. Students do achieve learning in practice, progress in practice when the theory is linked with practical life.

In order to achieve the target, from analysis to designing, students are forced to conduct deeply thinking to make comprehensive analysis about component characteristics and circuit function and new thinking sparks in the laboratory at the same time.

The push button is an indispensable component of the common man-machine input interface circuit which is simple in structure and strong in practicality. When the key denounce circuit is selected as the design theme for students to finish design themselves, students can do it in general circuit laboratory. The basic key debounce circuit is shown in Fig. 3. 


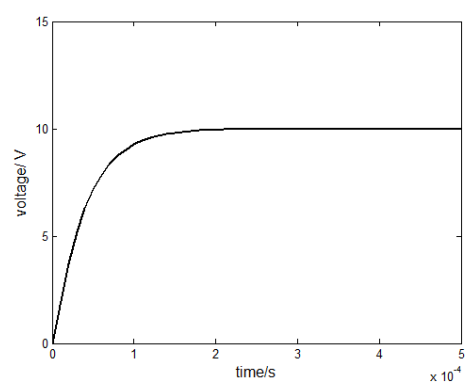

(a) Over-damping

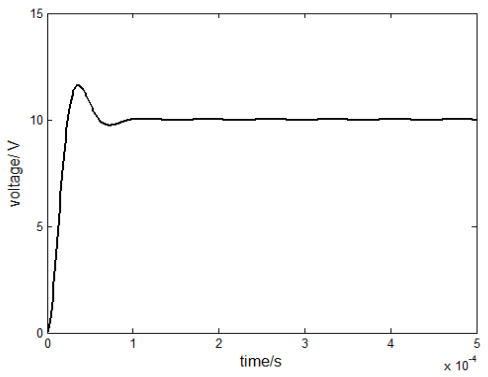

(c) Underdamping

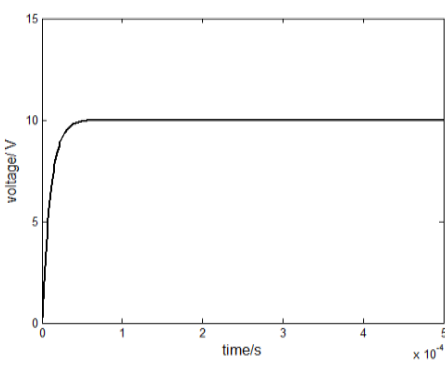

(b) Critical damping

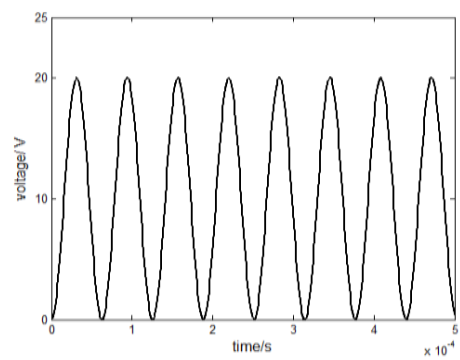

(d) Undamped oscillations

Fig. 2. Waveform

In order to achieve the target, from analysis to designing, students are forced to conduct deeply thinking to make comprehensive analysis about component characteristics and circuit function and new thinking sparks in the laboratory at the same time.

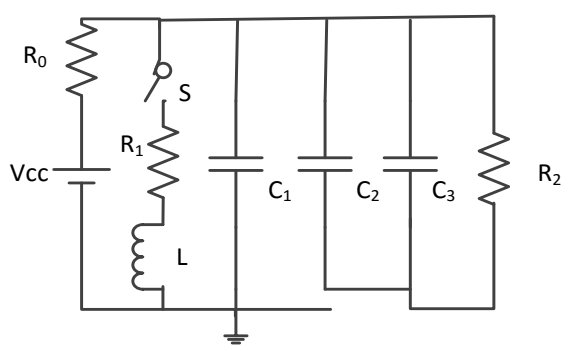

Fig. 3. The basic key debounce circuit

The push button is an indispensable component of the common man-machine input interface circuit which is simple in structure and strong in practicality. When the key debounce circuit is selected as the design theme for students to finish design themselves, students can do it in general circuit laboratory. The basic key debounce circuit is shown in Fig. 3.

The key debounce circuit is formed by the resistance, inductance and capacitance components, and the waveform can be observed through the oscilloscope. It requires no overshoot phenomenon appears when turn on the buttons and response time is less than $5 \mathrm{~ms}$. After the completion of the design, each group is required to show their design ideas and effect of the circuit to eliminate the chattering in five minutes, and teachers make the commenting about the design process and the achievement.

Many students suffered while the value of filter capacitor increase, the performance of filter improved but the overshoot problem stands out in the exploration generally. If a matching resistance added, the overshoot problem is solved while the filtering effect is guaranteed. In this design, students need to combine theoretical knowledge and experimental operation together, which makes the theoretical knowledge in students mind in sublimation, training the practical abilities and the ability of solving practical problems and students become the leader to do experiments.

In this design, students need to combine theoretical knowledge and experimental operation together, which makes the theoretical knowledge in students mind in sublimation, training the practical abilities and the ability of solving practical problems and students become the leader to do experiments.

Compared with the traditional experiment according to the wiring diagram to measure data the participation of students has increased obviously. In the curriculum evaluation after the experiment, teachers received favorable comments at the cost of the additional time to prepare the experiment in accordance with the students' thinking to connect the circuit and debugging the waveform.

\section{SUMMARY}

In student centered teaching on electric circuit course, focus on the establishment of circuit model, teaching as telling stories and exploring, students can receive more for teacher's good work.

\section{REFERENCES}

[1] Liu xian jun, "On the student-centered ideal". Journal of Higher Education, vol.33, pp. 1-6, Aug. 2012.

[2] Johnson L, Adams Becker S, Estrada V, ET al.The NMChorizon report. 2015

[3] Stecher B M,Hamilton L S.Measuring hard-to-measure student competencies. 2014 
[4] Zhang Rui, Wang Zuyuan, Xu Xiaofeng. "The research on instruction design for blended learning in internet environment" Physics and Engineering, vol.26, pp. 18-21, Mar. 2016.
[5] J.W.Nisslion, S.Riedel. Electric Circuits 9th [M].Prentice Hall, 2010 